\title{
TCOM \\ Panel-based exhibit using participatory design elements may motivate behavior change
}

\section{Lisa Lundgren, Kathryn A. Stofer, Betty A. Dunckel, Janice Krieger, Makenna Lange and Vaughan James}

\begin{abstract}
Meaningful science engagement beyond one-way outreach is needed to encourage science-based decision making. This pilot study aimed to instigate dialogue and deliberation concerning climate change and public health. Feedback from science café participants was used to design a panel-based museum exhibit that asked visitors to make action plans concerning such issues. Using intercept interviews and visitor comment card data, we found that visitors developed general or highly individualistic action plans to address these issues. Results suggest that employing participatory design methods when developing controversial socio-scientific exhibits can aid engagement. We conclude by recommending participatory strategies for implementing two-way science communication.
\end{abstract}

Keywords

DOI

Introduction
Community action; Public understanding of science and technology; Science centres and museums

https://doi.org/10.22323/2.18020203

Submitted: 24th October 2018

Accepted: 9th January 2019

Published: 5th February 2019
Our changing planet demands decision-making for people to adapt to different circumstances. However, human choices are not necessarily made using scientific rationale exclusively, but instead choices are influenced by our associates and what they believe [e.g. Bolsen, Druckman and Cook, 2014; Chittenden, Farmelo and Lewenstein, 2004; Kahan, 2008; Kahan, 2012; Suhay and Druckman, 2015; van der Linden et al., 2015]. Scientists may not be able to affect the process if they are seen as removed experts who are not engaged with the communities making decisions [Wynne, 1992; Wynne, 2006]. Therefore, to encourage science-based decision making, we need meaningful science engagement beyond traditional one-way outreach. Efforts towards this have been centered at science museums, such as at the Museum of Science, Boston, where a dialogic model of presenting socio-scientific issues has been implemented to promote meaningful science engagement [Kunz Kollmann et al., 2013]. With professional development programs, such as the National Network for Ocean and Climate Change 
Interpretation leadership program [Swim et al., 2017; Bunten and Arvizu, 2013], science museums and those who work within them can be crucibles for meaningful engagement with topics such as climate change. Museums can, and do, facilitate conversations about civic issues, but many may not take full advantage of their resources to do so [Kadlec, 2009; Stofer, 2015].

Exhibits, a conventional mode of interpretation and communication for museums, may reach large numbers of visitors but not promote dialogue [Davies et al., 2009; Zorn et al., 2012] or lead to behavior change [Prochaska and DiClemente, 1986]. Specifically, exhibits often follow a model of one-way, disseminatory outreach in which passive visitors read panels of texts which in turn educates them about a subject; however, such forms of outreach are ineffective, as people are more engaged in the learning process when two-way dialogues occur [Bucchi, 2008]. Programs that create in-person, public engagement such as science cafés require effort to do more than present knowledge in a one-way, didactic dissemination format, and even successful dialogue events may be difficult to scale [Lövbrand, Pielke and Beck, 2011]. To compare such formats head-to-head, we designed and implemented a pilot study that compared four methods of public engagement: traditional museum exhibit panels and three approaches building on the science café model. All four methods involved the audience in design of the content to promote engagement, including specifically inspiring community-level action beyond simply raising awareness about the issue. For the current article, we present the results of one of the four engagement methods: evaluating and describing the effectiveness of the museum exhibit panels, which we created based on input from science café participants and museum visitors, and were designed to provide an experience as parallel as possible to a science café. Results comparing our museum exhibit findings to those of the other three methods are in Stofer et al. [2019, submitted for publication].

Literature review

\section{Climate change and public health}

Despite its global importance, the connections between climate change and adverse human health effects often are drowned out by the focus on declining biodiversity and habitat loss. The relationship between climate change and health is important to consider, yet the complexity in considering human systems presents unique challenges [Portier et al., 2010]. The severity of adverse health effects caused by climate change include access to clean water and air as well as damages to homes and livelihoods due to drought, flooding, and other events [McMichael, Woodruff and Hales, 2006]. Higher ocean temperatures can lead to increased harmful algal blooms, decreased air quality, and agricultural issues [Haines et al., 2006] all of which have economic impacts [Almeida Prado et al., 2016; Havens, 2015]. Although these issues are severe, many people do not understand how they will be affected by climate change due to its global scale [Popovich, Schwartz and Schlossberg, 2017]. As climate change is both a local and a global issue, it must be framed as an issue that can be challenged and mitigated at personal, community, and global levels. 
To address socio-scientific issues such as climate change, public engagement with science has turned strongly towards educational and outreach events. In many cases, these events are designed to engage the public in conversation with scientists about current research in the form of science cafés [Dallas, 1999; Dallas, 2006]. Importantly, their philosophical foundation aims to move public engagement with science from transmission of factual knowledge to a social constructivist model. In the science café model, participants co-create knowledge with the professional researchers through experience and build on their previous understanding, in this case through dialogue [Davies et al., 2009]. Despite the café model's popularity and support by many scientific organizations [Davies et al., 2009; Stilgoe, Lock and Wilsdon, 2014], existing research on science cafés suggests cafés fall short of their dialogue goals [Lafrenière and Cox, 2012; Dijkstra, 2017]. Participation from the public comes primarily through discussion at the end of the event, with the content shaped by the café organizers and presenters.

Lafrenière and Cox [2012] confirm a difficulty with promoting events to a "general public" about whose motivations and interests organizers and presenters know little. However, even when the audience is already attentive to science, cafés may help improve participant attitudes toward and lower participant perceptions of risks of specific topics such as nanotechnology, [Dijkstra and Critchley, 2016] and evoke emotions such as empathy [Lafrenière and Cox, 2012]. These benefits from dialogue are of great interest as research demonstrates that familiarity with scientific topics alone does not always lead to more positive attitudes [Kahan, 2012]. While science cafés in their current form may never reach as many people as a museum exhibit, they have useful features that can be adapted by museum exhibits to encourage dialogue and deliberation. Such useful features include the ability for dialogue to occur amongst attendees, regardless of their status as scientist or member of the public, access to scientists (for the public), and access to the public (for scientists). For these reasons, we draw on research on and engagement intentions of the cafes to guide our exhibit design and to frame our analysis.

\section{Exhibit design}

Informal science learning institutions encourage learning and behavior changes, promoting public engagement with tangible objects as well as encouraging thoughtful dialogue, both of which serve to mediate the learning process [Luebke and Grajal, 2011; Davidsson and Jakobsson, 2012]. The long-term impacts of museum experiences have been demonstrated through longitudinal research on the trajectories of life-long learners and the propensity of young museum visitors to choose STEM careers [Falk, Dierking et al., 2016; Adams, Gupta and Cotumaccio, 2014]. However, other research shows that in many cases, the depth to which visitors conceptualize and retain knowledge gained from museum visits in the short-term is less impactful, as scientific concepts, such as microevolution and climate change, are difficult concepts for museum visitors to grasp [MacFadden et al., 2007; Gorr, 2014]. Barriers to knowledge construction are especially apparent when museum exhibits are not interactive and do not display authentic objects [Hampp and Schwan, 2014] or when visitors' conceptions do not align with exhibits [Patrick, 2016]. To alleviate such barriers, Kisiel and Ancelet [2009] suggest 
depicting evidence and providing entry points for visitors. In communicating climate change, other researchers suggest including explanatory metaphors and systems-level solutions in their dialogues with visitors and in exhibit text [Bales, Sweetland and Volmert, 2015]. Indeed, in communicating scientific topics to the public, many museums feature panel exhibits which have text and graphics about such topics. While museums are moving towards creating dialogue with visitors [e.g. Ramberg, Rand and Tomulonis, 2002], panel-exhibits remain the norm across many museums. Although a museum staple, these static exhibits have been shown to be less effective than interactive exhibits that include touch-screens, technological gadgetry, or feedback mechanisms for visitors to leave thoughts and comments [Lin, 2007], which leads to the notion that further development and evaluation of interactive exhibits is needed, especially in the realm of climate change and public health.

\section{Informal science learning centers and behavioral change}

The design of exhibit content can influence affective interest. As visitors' background content knowledge increases, the more pleasurable their visit will be [Dahl et al., 2013]. Indeed, in researching the connections between visitor engagement and scientific understanding, Bandelli and Konijn [2015] found that visitors needed such background knowledge to engage with exhibits on a base level, but were more inclined to co-create exhibit content if they had previous interactions with the museum itself, not the content specifically. If museums intend to elicit behavioral change with issues such as climate change, exhibits must move beyond the mere display of such politicized scientific concepts. These concepts, including vaccinations and climate change, tend to encourage individualized actionable responses such as vaccinating one's own children and pledging to recycle more to reduce greenhouse emissions.

While individual actions are positive, larger solutions such as political action require inputs that are collective and take place at a group level [Ordner, 2017]. To better situate scientific concepts, encourage group action, and meet visitor needs, we applied Simon's [2010] framework for participatory exhibit design.

Participatory exhibit design contends that visitor participation occurs in stages, where visitors are able to move between passive content consumption to engaging with each other socially and creating exhibit content. The participatory design process effectively captures visitors' diverse needs and backgrounds and allows them to participate with an exhibit to the degree with which they are comfortable. Participatory design can situate visitors in multiple actionable levels, from individualized action to group actions.

Method

The purpose of this article is to evaluate the effectiveness of the participatory design process on the development of a climate change exhibit, examine the ways the exhibit engaged visitors, and evaluate the ways the exhibit elicited behavior change in visitors. Our research questions are as follows:

1. How effective is the use of the participatory exhibit design process in engaging visitors when designing an exhibit about climate change and public health? 
2. What group-level actions about climate change do museum exhibits motivate, as evidence of engagement with the exhibit beyond content delivery?

We addressed our research questions using a two-pronged approach: soliciting input regarding the content of the exhibit and capturing visitor feedback while the exhibit was installed. We solicited input from museum visitors and science café attendees using design intercept interviews. Responses gathered from these intercept interview responses served as the basis for developing the museum exhibit. During the time period in which the museum exhibit was installed, we captured visitor engagement, knowledge gain, and change in behavioral intent using qualitative methods (i.e. evaluation intercept interviews and comment cards installed in the exhibit) at a natural history museum affiliated with a southeastern, United States-based university.

\section{Participants and data collection procedure}

\section{Exhibit panel participatory design}

To derive topics for the exhibit using participatory design principles [Simon, 2010], we solicited input using design intercept interviews with museum visitors and surveys completed by science café audiences $(n=51)$. In addition, we attempted to solicit feedback via an online survey advertised in the local newspaper; however, this survey garnered no responses. We asked participants about their concerns regarding the impact of climate change on their personal health and the health of their community, as well as what actions they thought they could take to combat climate change and improve their health. The results of the design intercept interviews at the museum and science cafe surveys provided the foundation for the exhibit content development and design. Four authors individually coded museum visitor and science café participant responses, then the four authors discussed coding in a series of weekly meetings until reaching consensus [Saldaña, 2013]. Two content themes encapsulated science café participant and museum visitor responses: 1) water quality and 2) allergies, asthma, and air quality; these two themes became the basis for the six-panel museum exhibit. We will discuss the procedure for deriving these themes in the data analysis and results sections of this article.

\section{Exhibit design and comment card data collection}

In addition to providing background content on climate change and public health, the main goal of the exhibit was to encourage community-level (rather than simply individual) action for local health and climate change issues related to air and water quality. Such community-level actions were described as creating an "action plan," which was a theme throughout the exhibit panels. The exhibit included a pseudo-interactive and an interactive component: an air quality monitor and a comment card panel. The air quality monitoring system measured indoor and outdoor air quality including carbon dioxide and particulate matter, as such, it did not encourage visitors to change settings or interact per se, however, visitors could interact by comparing the air quality in the museum to the air quality of cities within the southeastern state, as well as by downloading the affiliated air quality monitoring app on their phones. Another panel, which was interactive in nature, 
featured a board with cards and pencils for sharing action plans (Figure 1).

Comment cards were open-response, allowing visitors to describe something they wanted to protect, the action they would take to protect it, and the people with whom they would take action. Comment cards were collected from the exhibit at the end of each visiting day in late 2016 and early $2017(N=151)$.
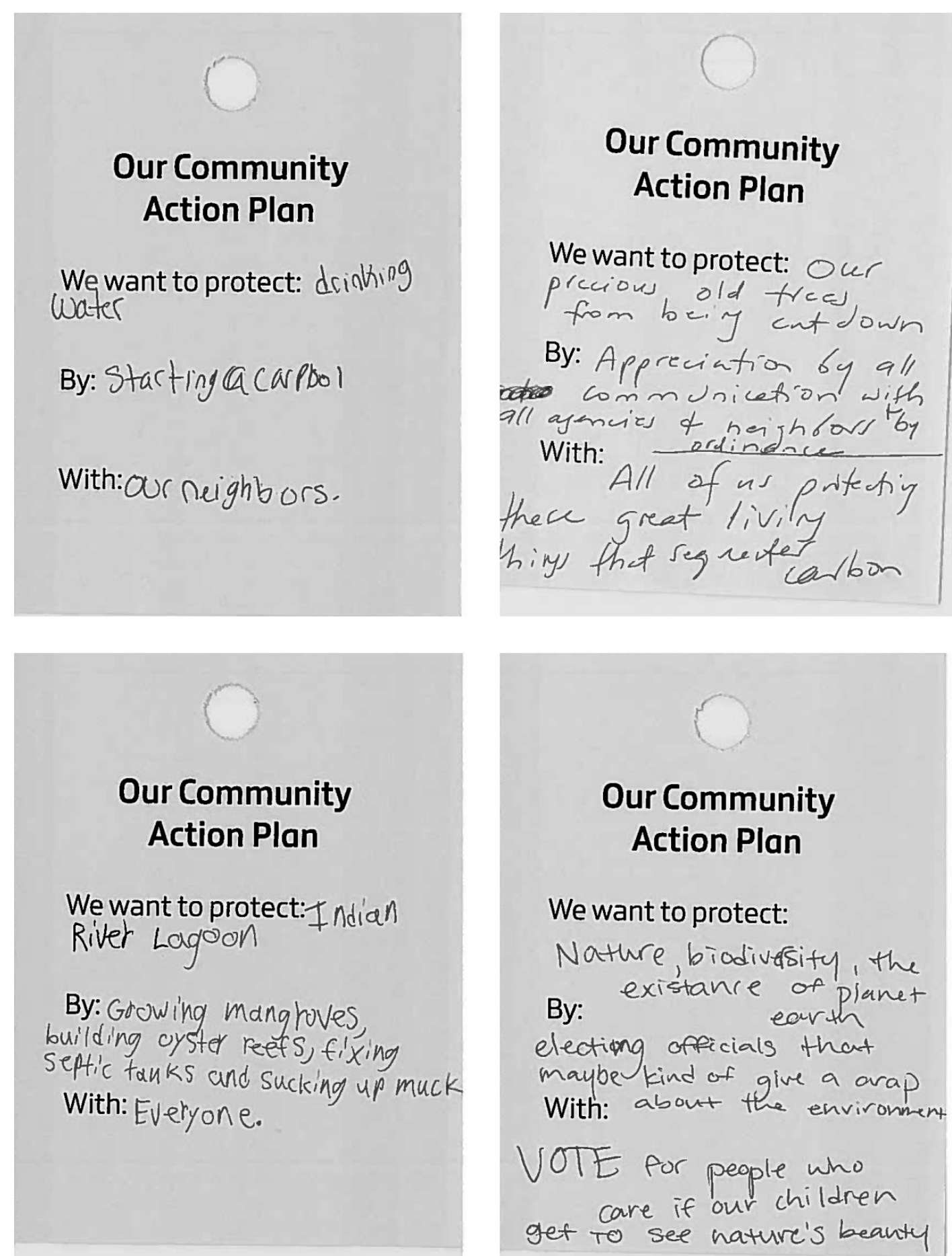

Figure 1. Examples of visitor-created community action plans.

These six panels were installed in late 2016 in the atrium gallery of a university-affiliated natural history museum within the southeastern United States. During the display period (late 2016-early 2017), we interviewed thirteen groups 
who viewed the panel. Researchers approached every other visitor group who was observed reading or interacting with the panel exhibit and included at least one adult, asking the group to participate in a brief, three-question interview.

Researchers recorded notes on the participant responses. Two of the authors then applied thematic qualitative coding, grouping responses into categories for each question [Gibbs, 2007].

There are limitations involved in the collection and analysis of these pilot study data, including the select audience (i.e. current museum visitors and participants from a museum-sponsored science café) through whom we collected data. This exploratory qualitative study [Merriam and Tisdell, 2016] involved open-response interview and survey data. The findings presented here are not generalizable nor representative; data were not collected randomly. Despite these limitations, this research addresses a knowledge gap in the field of science communication, providing foundational understandings of how participatory design can be used in developing museum exhibits that concern socio-scientific issues. Our results will likely be transferable to other contexts [Lincoln and Guba, 1985] based on our thick descriptions of our context.

\section{Analysis Procedure}

Analysis involved two phases, first, analyzing data collected from design intercept interviews and surveys from science café participants, and then analyzing data collected during the exhibit's display period (Figure 2).

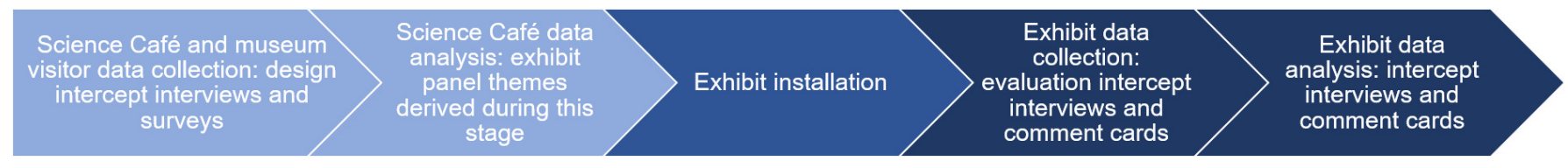

Figure 2. Data collection and analysis procedure.

Analyzing design intercept interviews and surveys from science café participants and museum visitors comprised the first stage of analysis; these responses were examined through a process of emergent coding and constant comparative analysis [Glaser, 1965]. First, research assistants individually coded responses, focusing on the descriptions of public health concerns that participants described. Then the whole research team met, comparing responses and discussing them to consensus. These responses were used to develop the exhibit content.

After panels were installed, the authors conducted evaluation intercept interviews and collected exhibit comment cards which were analyzed using thematic qualitative analysis [Saldaña, 2013]. The cards and interviews were first individually coded for high-level themes focusing on what visitors said they wanted to protect (i.e. air quality, water, the environment, off topic, etc.). Next, card and interview responses were coded as local versus non-local. Incomplete cards and cards containing fictional protection targets or groups (e.g., with Superman and friends) were then removed. Following this, cards and interviews were coded based on if the actions depicted took place with a group (e.g., Girl Scouts or a local stream protection club) or were individualized (e.g., writing a letter to the editor). Lastly, cards and interviews were coded for specific group actions and non-specific 
community level actions, such as hosting a public citizen science water monitoring event with Girl Scouts (i.e. a specific group action).

Responses we honed in on are those concerning specific group-level actions ( $n=$ 47). This process revealed that 34 out of a total of 151 exhibit comment cards were related to group-level actions about public health and climate change and all of the evaluation intercept interviews concerned group-level actions of some sort. The first and second author then discussed these comment cards and the evaluation intercept interviews to consensus, determining six specific categories: litter- and pollution-focused, communication- and education-focused, political- or law-focused, carpooling, no specific plan, and other/uncategorized.

Our first research question sought to evaluate the effectiveness of the participatory design process when designing an exhibit about climate change and public health. Using a design intercept interview and open-ended surveys, we asked museum visitors and science café participants about their concerns regarding climate change and their health, as well as what actions they or their community could take to combat climate change (Table 1). Two major themes emerged: a focus on allergies/air quality and water quality. These themes formed the baseline content for the panel exhibit.

Table 1. Summary of coded responses from science café surveys and design intercept interviews with museum visitors.

\begin{tabular}{|lr|}
\hline Code Category & Frequency of code $(N=51)$ \\
\hline Allergies and air quality & 16 \\
Water quality & 16 \\
"I don't know" & 19 \\
\hline
\end{tabular}

Many responses gathered from design intercept interview and science café surveys indicated allergies and air quality $(n=16)$. This response is seen in the science café survey respondent who wrote that climate change, "lengthens allergy season (and I suffer from allergies and asthma)." Another group of visitors wondered about climate change's effect on their children due to increased allergies and pollen control. This theme also emerged in the response of a science café survey respondent who wrote that it "appears to be summer year-round here which negatively impacts my sinus problems." Another respondent wrote that climate change will expedite health issues, such as "asthma and breathing problems," which was echoed in the response from another survey respondent who expressed that climate change affected "air purity and ability to walk/exercise outside." An older person also reflected on climate change's effects, writing: "Being in my 60's the health effects in [southeastern state] for me will be less than future generations... [but] change in local environs, droughts possible, new or invasive allergens."

Respondents also sought to understand more about water quality $(n=16)$, with some respondents simply answering "quality of water" and "water supply" when asked "what concerns do you have about the impact of climate change and your health?" One respondent, who indicated they worked on ecosystems, wrote that climate change "increases zoonotic diseases (e.g. malaria)... as stream temp rises." 
Some respondents said climate change was going to impact clean water, while others expressed concerns about state-specific water resources, telling the researcher they had great concern for the "health of local springs" and wondered if rules would be implemented to help regulate "care of water." One respondent even indicated particular concern with the effects of people being asked to move from septic to city sewers, wondering how that could affect water quality.

However, many respondents $(n=19)$ also responded with some iteration of "I don't know" or indicated that they wanted to know broad and general information about climate change and public health. Such responses included visitors who said, "What can the community do that can be put into practice?" and another group who said, "I don't know, is global warming real? What actions can the community take?" A different respondent wrote that they wanted to know "everything I should know to protect my family and be an advocate in the community." While our focus was on community changes and communal level actions, many respondents wanted to know how they personally could address climate change, as indicated in the response, "better understanding of impact of individual decisions and behaviors vis-a-vis impact of agriculture/manufacturing, etc."

Overall, the use of participatory design was successful in that we garnered responses from community members in order to create an exhibit. However, the responses show a distinct level of uncertainty surrounding climate change.

\section{Exhibit evaluation results}

To address our second research question, "What group-level actions about climate change do museum exhibits motivate?", we examined responses from evaluation intercept interviews $(n=13)$ and examined visitor comment cards $(n=34)$ (Table 2$)$. For the intercept interviews and visitor comment cards, group-level actions were assigned to six categories: litter- and pollution-focused, communication- and education-focused, political- or law-focused, carpooling, no specific plan, and other/uncategorized. Participant identities were not recorded during the evaluation intercept interviews nor on the exhibit comment cards. Therefore, participants and comment cards were given numerical values (e.g. Intercept Interview \#2, Comment Card \#21) to distinguish between them.

Table 2. Coding categories of group-level actions and frequencies from comment cards and evaluation intercept interviews.

\begin{tabular}{|lr|}
\hline Code Category & Frequency of code $(N=47)$ \\
\hline Litter and pollution-focused & 10 \\
Communication and education-focused & 7 \\
Law-focused & 6 \\
Carpooling & 4 \\
No plan & 4 \\
Other/Uncategorized & 16 \\
\hline
\end{tabular}

Carpooling and political group-level actions were given less frequently, while litter or pollution specific and vague actions were given the most frequently. Through this process, we found that many visitors engaged with the exhibit because of their interest in specific topics. Five interviewees indicated that the general topic of 
climate change drew their interest, whereas five others said the topic of allergies attracted them, and two interviewees were drawn to the exhibit because of an interest in water. The people who were drawn to the exhibit by allergies or water quality indicated the specific panel title caught their attention.

In examining comment cards and interviews, the least coded responses were those that contained group-level actions about carpooling $(n=4)$, judicial level group-actions $(n=6)$, and education actions $(n=7)$. Of the four responses concerning carpooling as a group-level action, respondents explained its importance by indicating carpooling could protect a variety of places and things including the air, drinking water, and "panda's snowcapped mountains" (Comment Card \#87). Those responses concerning judicial group-level actions, indicated political and law-focused actions such as protecting "animals" by controlling development through "rules and laws" (Comment Card \#26). Others left comments related to voting and political action, such as "encouraging politicians to do climate control" (Intercept Interview \#6) "electing officials that maybe kind of give a crap about the environment" (Comment Card \#83) and acting by taking "any political action and protest possible" (Comment Card \#86). In terms of group-level actions that centered on education and communication, responses left on comment cards featured particular places to protect, such as local rivers (Comment Cards \#20 and \#131) and other places in nature. To enact such protection, commenters and those interviewed indicated non-specific group-level actions such as "continuing conservation efforts and education [about] the [state] aquifer" (Comment Card \#39).

The most common specifically defined group-level actions concerned litter and pollution $(n=10)$. On these cards and in these interviews, respondents depicted ways in which group-level actions could be taken to keep the environment clean, "doing stuff for pollution" (Intercept Interview \#3) to "reducing litter" (Comment Card \#30), to keeping rivers and springs in a certain county clean by "not throwing trash in them" (Comment Card \#9) and by "preventing pollution" (Comment Card \#20). These pollution and litter-centric actions were all designated as group-level actions as each respondent portrayed people with whom they would take these actions with. However, like most other responses, the groups with whom these actions could be completed were nebulous, such as "our neighbors, classmates, families, and friends" (Comment Card \#9) and "the whole world" (Comment Card \#105).

Responses that contained group-level actions concerning climate change and public health most often could be generalized to the category of "other" in that the group-level actions were either vague or the people with whom the action could be completed were vaguely defined $(n=16)$. For example, visitors who filled out cards placed within this category indicated that they wanted to make change with "friends, family" (Comment Card \#87) or "the people of the universe" (Comment Card \#126). While these answers are groups, the specificity with which action concerning climate change could be taken was lacking. Other responses within this category denoted specific places to protect using specific actions. Such examples included the interviewee who indicated they would "go home and google it to look into the monitor" and the comment card which depicted protecting the "Indian River Lagoon by growing mangroves, building oyster reefs, fixing septic tanks and sucking up muck" (Comment Card \#127). However, in indicating that the Indian River Lagoon needed protection, the comment card did not indicate with whom this group-level action could occur, going only far enough as to say "everyone." 
In short, the ways in which museum visitors engaged with a panel-based exhibit concerning climate change and public health initiated several lines of evidence to explore. The first is that of participatory design process as it was used in designing an exhibit about climate change and public health and the way it can be considered as it relates to critical museology [Shelton, 2013]. Within this conceptualization, museums can rearticulate or reimagine knowledge structures from participants from across the continuum of expertise. Within critical museology, participation, dialogue, plurality, and the consideration of social contexts are paramount. In our pilot study, we found that encouraging such perspectives can positively affect the ways museum visitors engage with exhibit content as well as have an effect on visitors' inclinations to take action concerning public health and climate change.

Indeed, for participatory exhibit design to be truly effective, one has to reach outside the boundaries of traditional museum goers [Cardiel et al., 2016]. Although we sought exhibit feedback from those outside the traditional museum visitor by placing surveys in newspapers, we did not receive any responses in this manner. As such, only current museum visitors and participants from a museum-sponsored science café gave feedback during the design phase which was used to create the exhibit topics. To improve upon this study, other researchers will need to seek alternative methods for soliciting feedback from non-traditional museum goers. When seeking to understand behavioral change and group-level actions, the small number of visitors we interviewed coupled with the minimized pool of comment card responses makes it difficult to generalize. The localized content focus prevents some transferability, but in general, our descriptions of the ways in which visitors engage with controversial scientific concepts aligns with previous research [Gorr, 2014]. We suggest that behavior change intention can be incorporated into the study of public engagement with politicized scientific topics in museums and other informal learning environments.

\section{Future research recommendations}

Overall, we found promising evidence of the ability of an exhibit to motivate action beyond simply raising awareness of an issue. Further results of the exhibit evaluation compared to the science cafés in this regard can be found in Stofer et al. [2019, submitted for publication]. Future research should examine whether people carry through with actions. Additional research should be done on other climate change-centric exhibits, although following recommendations by MacFadden et al. [2007], such topics should be integrated into natural history exhibits rather than being isolated topics. Furthermore, the emphasis on group-level action in regards to climate change as recommended by Ordner [2017] must be examined fully in the context of museums and informal education. Cameron [2012] highlighted the changing roles of museums and their turn toward collective action, indicating that group-level actions allow for more robust science practices across the world. Some museums, including those which emphasize art and history, have addressed integrating controversial issues [see Johnson-Cunningham, 2018], such as the Ronald Reagan Presidential Library, which employed a forum and partnership strategy to address information literacy [de los Santos, Smith and Cohen, 2018]. However, science museums must catch up to other cultural institutions in their strategies for centering controversial socio-scientific issues. Employing all of Simon's participatory design methods when developing controversial socio-scientific exhibits is likely to aid in visitor engagement but should be examined to assess its effectiveness and inform practice. 


\section{Exhibit design recommendations}

Museum exhibits cannot shy away from presenting "controversial" scientific topics, as these topics can present compelling contexts which encourage the consideration of diverse perspectives [Pedretti and Navas-Iannini, 2018]. In designing exhibits that focus on controversial scientific issues that have societal impact, such as vaccinations, climate change, and evolution, we offer two design recommendations, echoing those found in previous research concerning controversial exhibits [Pedretti and Dubek, 2014], exhibits on evolution [MacFadden et al., 2007] and on virology [Diamond et al., 2015]: integrating controversial topics and using a wide array of programming to reach varied audiences. We also offer a recommendation for producing more effective exhibit comment cards based on recommendations by Simon [2010].

In their research, Pedretti and Dubek [2014] indicated that controversial or critical museum exhibits allow for diverse audiences to examine the ways in which scientific truths are constructed as well as emphasize the sociocultural influences that exist when conducting scientific research. Encouraging multiple forms of participation, as stressed by Simon [2010] can foment consideration of such issues. Indeed, Diamond et al. [2015] stressed the importance of complementary outreach programs to reach various audiences because highlighting the local connections heightened perceptions of critical issues. Indeed, a visitor in this study commented that the air quality monitor in the exhibit interested him because it allowed him to assess the air quality of his city comparatively: while he thought his city had a good rating on the air quality scale, he was intrigued because it did not feel like he had good air quality.

In order to receive more effective exhibit engagement with comment cards, improved prototyping of the cards is needed. While we gained key insights through multiple rounds of prototyping the comment cards, the open-ended nature of the cards lacked some substance. Therefore, we recommend additional prototyping as well as implementing structured, threaded comment cards in place of simply structured comment cards [Simon, 2010]. With structured and threaded comment cards, one visitor or group of visitors begins the structure of the comment card with an "idea card" and other visitors add "good idea" cards and "That makes me think about..." cards to the original card. In this manner, the interactive design (i.e. comment cards) inspires dialogue, with some content arising from the panel exhibit itself.

\section{Conclusion}

Adapting to climate change requires decision-making. In this study, we sought to answer two research questions: How effective is the use of the participatory exhibit design process when designing an exhibit about climate change and public health? and What group-level actions about climate change do museum exhibits motivate as evidence of engagement with the exhibit beyond content delivery?

To answer our first question, we sought community feedback from science café participants as well as museum visitors, finding that allergies and air quality along with water quality were key concerns. To engage with these concerns, we designed a panel exhibit, following some of the best practices as outlined by Simon [2010]. Although our design process did not fully encapsulate all of Simon's components, 
we embraced her principles for collaborating with visitors by providing opportunities for participants to inform the content development of the exhibit based on their specific concerns [Visser, 2010]. We found the participatory design process to be moderately successful for this project and very important as we refined the exhibit focus.

Second, we sought to learn how group-level actions regarding climate change may be motivated by museums. Through intercept interviews and examination of visitor comment cards, we found that visitors have vague notions of group-level actions and ambiguous suggestions for taking these actions. On the exhibit comment cards, a number of visitors were willing to contribute their thoughts, but the majority of the cards lacked a local connection, a community-level action, or both. The lack of on-topic, robust responses aligns with other research into the ways in which families and groups behave in museums [Diamond, 1986; Falk and Dierking, 2013].

Thus, we conclude with the notion that participatory exhibit design offers visitors, researchers, and designers opportunities to make decisions as our changing planet demands us to adapt. Climate change and public health concern all. As cultural touchpoints for discussion, keepers of culture, and stewards for the future, museums and the exhibits within them can be designed around climate change by harnessing the power of participatory design principles to move beyond raising awareness of issues to motivating group actions to address issues.

Acknowledgments The authors would like to thank the museum staff for help with data collection logistics as well as exhibit layout and production.

\section{References}

Adams, J., Gupta, P. and Cotumaccio, A. (2014). 'Long-term participants: a museum program enhances girls' STEM interest, motivation and persistence'. Afterschool Matters 20 (Fall), pp. 13-20. URL: https://eric.ed.gov/?id=EJ1047233.

Almeida Prado, F., Athayde, S., Mossa, J., Bohlman, S., Leite, F. and Oliver-Smith, A. (2016). 'How much is enough? An integrated examination of energy security, economic growth and climate change related to hydropower expansion in Brazil'. Renewable and Sustainable Energy Reviews 53, pp. 1132-1136. https://doi.org/10.1016/j.rser.2015.09.050.

Bales, S. N., Sweetland, J. and Volmert, A. (2015). How to talk about climate change and the ocean: a FrameWorks MessageMemo. Washington, DC, U.S.A.

URL: https://frameworksinstitute.org/assets/files/PDF_oceansclimate /climatechangeandtheocean_mm_final_2015.pdf.

Bandelli, A. and Konijn, E. A. (2015). 'Public Participation and Scientific Citizenship in the Science Museum in London: Visitors' Perceptions of the Museum as a Broker'. Visitor Studies 18 (2), pp. 131-149. https://doi.org/10.1080/10645578.2015.1079089.

Bolsen, T., Druckman, J. N. and Cook, F. L. (2014). 'The Influence of Partisan Motivated Reasoning on Public Opinion'. Political Behavior 36 (2), pp. 235-262. https://doi.org/10.1007/s11109-013-9238-0.

Bucchi, M. (2008). 'Of deficits, deviations and dialogues: theories of public communication of science'. In: Handbook of Public Communication of Science and Technology. Ed. by M. Bucchi and B. Trench. London, U.K. and New York, U.S.A.: Routledge, pp. 57-76. 
Bunten, A. and Arvizu, S. (2013). 'Turning visitors into citizens: using social science for civic engagement in informal science education centers'. Journal of Museum Education 38 (3), pp. 260-272. https://doi.org/10.1080/10598650.2013.11510778.

Cameron, F. R. (2012). 'Climate change, agencies and the museum and science centre sector'. Museum Management and Curatorship 27 (4), pp. 317-339. https://doi.org/10.1080/09647775.2012.720183.

Cardiel, C. L. B., Pattison, S. A., Benne, M. and Johnson, M. (2016). 'Science on the move: a design-based research study of informal STEM learning in public spaces'. Visitor Studies 19 (1), pp. 39-59. https://doi.org/10.1080/10645578.2016.1144027.

Chittenden, D., Farmelo, G. and Lewenstein, B. V., eds. (2004). Creating Connections: Museums and the Public Understanding of Current Research. Lanham, MD, U.S.A.: AltaMira Press.

Dahl, T. I., Entner, P. S., Johansen, A.-M. H. and Vittersø, J. (2013). ‘Is our fascination with museum displays more about what we think or how we feel?' Visitor Studies 16 (2), pp. 160-180. https: //doi .org/10.1080/10645578.2013.827011.

Dallas, D. (1999). 'Science in culture'. Nature 399 (6732), pp. 120-120. https://doi.org/10.1038/20118.

- (2006). 'Café Scientifique - Déjà Vu'. Cell 126 (2), pp. 227-229. https://doi.org/10.1016/j.cell.2006.07.006.

Davidsson, E. and Jakobsson, A., eds. (2012). Understanding interactions at science centers and museums. Rotterdam, The Netherlands: SensePublishers. https://doi.org/10.1007/978-94-6091-725-7.

Davies, S., McCallie, E., Simonsson, E., Lehr, J. L. and Duensing, S. (2009). 'Discussing dialogue: perspectives on the value of science dialogue events that do not inform policy'. Public Understanding of Science 18 (3), pp. 338-353. https://doi.org/10.1177/0963662507079760.

de los Santos, T. M., Smith, E. and Cohen, M. (2018). 'Targeting truth: how museums can collaboratively address social issues'. Journal of Museum Education 43 (2), pp. 104-113. https: //doi .org/10.1080/10598650.2018.1457842.

Diamond, J. (1986). 'The behavior of family groups in science museums'. Curator: The Museum Journal 29 (2), pp. 139-154. https://doi.org/10.1111/j.2151-6952.1986.tb01434.x.

Diamond, J., Jee, B., Matuk, C., McQuillan, J., Spiegel, A. N. and Uttal, D. (2015). 'Museum monsters and victorious viruses: improving public understanding of emerging biomedical research'. Curator: The Museum Journal 58 (3), pp. 299-311. https://doi.org/10.1111/cura.12115.

Dijkstra, A. (2017). 'Analysing Dutch Science Cafés to better understand the science-society relationship'. JCOM 16 (01), A03. https://doi.org/10.22323/2.16010203.

Dijkstra, A. M. and Critchley, C. R. (2016). 'Nanotechnology in Dutch science cafés: Public risk perceptions contextualised'. Public Understanding of Science (Bristol, England) 25 (1), pp. 71-87. https ://doi .org/10.1177/0963662514528080. PMID: 24812210.

Falk, J. H. and Dierking, L. D. (2013). The museum experience revisited. Walnut Creek, CA, U.S.A.: Left Coast Press Inc. 
Falk, J. H., Dierking, L. D., Swanger, L. P., Staus, N., Back, M., Barriault, C., Catalao, C., Chambers, C., Chew, L.-L., Dahl, S. A., Falla, S., Gorecki, B., Lau, T.-C., Lloyd, A., Martin, J., Santer, J., Singer, S., Solli, A., Trepanier, G., Tyystjärvi, K. and Verheyden, P. (2016). 'Correlating science center use with adult science literacy: an international, cross-institutional study'. Science Education 100 (5), pp. 849-876. https://doi.org/10.1002/sce.21225.

Gibbs, G. (2007). Analyzing qualitative data. London, U.K.: SAGE Publications Ltd. https://doi.org/10.4135/9781849208574.

Glaser, B. G. (1965). 'The constant comparative method of qualitative analysis'. Social Problems 12 (4), pp. 436-445. https://doi .org/10.2307/798843.

Gorr, C. (2014). 'Changing climate, changing attitude?' Museums $\mathcal{E}$ Social Issues 9 (2), pp. 94-108. https://doi.org/10.1179/1559689314z.00000000021.

Haines, A., Kovats, R. S., Campbell-Lendrum, D. and Corvalan, C. (2006). 'Climate change and human health: impacts, vulnerability and public health'. Public Health 120 (7), pp. 585-596. https://doi.org/10.1016/j.puhe.2006.01.002.

Hampp, C. and Schwan, S. (2014). 'The role of authentic objects in museums of the history of science and technology: findings from a visitor study'. International Journal of Science Education, Part B 5 (2), pp. 161-181. https://doi.org/10.1080/21548455.2013.875238.

Havens, K. (2015). Climate change and the occurrence of harmful microorganisms in Florida's ocean and coastal waters. Gainesville, FL, U.S.A. URL: http://edis. ifas.ufl. edu/pdffiles/SG/SG13600.pdf.

Johnson-Cunningham, S. (2018). 'Beyond gallery walls and performance halls: five essential steps museums and other cultural institutions must take to center people, communities and cultivate effective societal change'. Museums $\mathcal{E}$ Social Issues 13 (1), pp. 2-7. https: //doi .org/10.1080/15596893.2018.1480852.

Kadlec, A. (2009). 'Play and public life'. National Civic Review 98 (4), pp. 3-11. https://doi.org/10.1002/ncr. 270.

Kahan, D. M. (2008). 'Two conceptions of emotion in risk regulation'. Yale Law School faculty scholarship series, 99. URL: http://digitalcommons. law.yale.edu/fss_papers/99.

Kahan, D. M. (2012). 'Cognitive bias and the constitution of the liberal republic of science'. Yale Law School, Public Law Working Paper, 270. https://doi.org/10.2139/ssrn. 2174032.

Kisiel, J. and Ancelet, J. (2009). 'Uncovering visitor conceptions of fossils and the fossil record'. Visitor Studies 12 (2), pp. 133-151. https://doi.org/10.1080/10645570903203422.

Kunz Kollmann, E., Reich, C., Bell, L. and Goss, J. (2013). 'Tackling tough topics: using socio-scientific issues to help museum visitors participate in democratic dialogue and increase their understandings of current science and technology'. Journal of Museum Education 38 (2), pp. 174-186. https://doi.org/10.1080/10598650.2013.11510768.

Lafrenière, D. and Cox, S. M. (2012). 'Means of Knowledge Dissemination: Are the Café Scientifique and the Artistic Performance Equally Effective?' Sociology Mind 02 (02), pp. 191-199. https://doi .org/10.4236/sm.2012.22025.

Lin, S. (10th July 2007). 'The interactive aquarium: evaluating the effectiveness of interactive interfaces in an aquarium visit'. Journal of Young Investigators.

URL: https://www . jyi .org/2007-july/2007/7/10/the-interactive-aquariu m-evaluating-the-effectiveness-of-interactive-interfaces-in-an-aqua rium-visit. 
Lincoln, Y. S. and Guba, E. G. (1985). Naturalistic inquiry. Los Angeles, CA, U.S.A.: SAGE Publications, Inc.

Lövbrand, E., Pielke, R. and Beck, S. (2011). 'A democracy paradox in studies of science and technology'. Science, Technology, E Human Values 36 (4), pp. 474-496. https://doi.org/10.1177/0162243910366154.

Luebke, J. F. and Grajal, A. (2011). 'Assessing mission-related learning outcomes at zoos and aquaria: prevalence, barriers and needs'. Visitor Studies 14 (2), pp. 195-208. https://doi.org/10.1080/10645578.2011.608013.

MacFadden, B. J., Dunckel, B. A., Ellis, S., Dierking, L. D., Abraham-Silver, L., Kisiel, J. and Koke, J. (2007). 'Natural history museum visitors' understanding of evolution'. BioScience 57 (10), pp. 875-882. https://doi.org/10.1641/b571010.

McMichael, A. J., Woodruff, R. E. and Hales, S. (2006). 'Climate change and human health: present and future risks'. The Lancet 367 (9513), pp. 859-869. https://doi.org/10.1016/s0140-6736 (06)68079-3.

Merriam, S. B. and Tisdell, E. J. (2016). Qualitative research: a guide to design and implementation. 4th ed. San Francisco, CA, U.S.A.: Jossey-Bass.

Ordner, J. P. (2017). 'Community action and climate change'. Nature Climate Change 7 (3), pp. 161-163. https://doi.org/10.1038/nclimate3236.

Patrick, P. G. (2016). 'Visitors and alignment: actor-network theory and the ontology of informal science institutions'. Museum Management and Curatorship 32 (2), pp. 176-195. https://doi.org/10.1080/09647775.2016.1239126.

Pedretti, E. and Dubek, M. (2014). 'Critical issues-based exhibitions'. In: Encyclopedia of science education. Ed. by R. Gunstone. Dordrecht, The Netherlands: Springer Netherlands, pp. 1-3. https://doi.org/10.1007/978-94-007-6165-0_339-2.

Pedretti, E. and Navas-Iannini, A. M. (2018). 'Pregnant pauses: science museums, schools and a controversial exhibition'. In: Navigating the changing landscape of formal and informal science learning opportunities. Ed. by D. Corrigan, C. Buntting, A. Jones and J. Loughran. Cham, Switzerland: Springer International Publishing, pp. 31-49. https://doi.org/10.1007/978-3-319-89761-5_3.

Popovich, N., Schwartz, J. and Schlossberg, T. (17th March 2017). 'How Americans think about climate change, in six maps'. The New York Times.

URL: https://www.nytimes . com/interactive/2017/03/21/climate/how-amer icans-think-about-climate-change-in-six-maps.html.

Portier, C. J., Thigpen Tart, K., Carter, S. R., Dilworth, C. H., Grambsch, A. E., Golke, J., Hess, J., Howard, S. N., Luber, G., Lutz, J. T., Maslak, T., Prudent, N., Radtke, M., Rosenthal, J. P., Rowles, T., Sandifer, P. A., Scheraga, J., Schramm, P. J., Strickman, D., Trtanj, J. M. and Whung, P.-Y. (2010). A human health perspective on climate change: a report outlining the research needs on the human health effects of climate change. U.S.A.: National Institute of Environmental Health Sciences.

URL: http://www.niehs.nih.gov/climatereport.

Prochaska, J. O. and DiClemente, C. C. (1986). 'Toward a comprehensive, transtheoretical model of change'. In: Treating addictive behaviors. Applied clinical psychology. Ed. by W. R. Miller and N. Heather. Vol. 13. Boston, MA, U.S.A.: Springer U.S., pp. 3-24.

https://doi.org/10.1007/978-1-4613-2191-0_1. 
Ramberg, J. S., Rand, J. and Tomulonis, J. (2002). 'Mission, message and visitors: how exhibit philosophy has evolved at the Monterey bay aquarium'. Curator: The Museum Journal 45 (4), pp. 302-320. https://doi.org/10.1111/j.2151-6952.2002.tb00067.x.

Saldaña, J. (2013). The coding manual for qualitative researchers. 2nd ed. Los Angeles, CA, U.S.A.: SAGE.

Shelton, A. (2013). 'Critical museology'. Museum Worlds 1 (1), pp. 7-23. https://doi.org/10.3167/armw .2013.010102.

Simon, N. (2010). The participatory museum. Santa Cruz, CA, U.S.A.: Museum 2.0. Stilgoe, J., Lock, S. J. and Wilsdon, J. (2014). ‘Why should we promote public engagement with science?' Public Understanding of Science 23 (1), pp. 4-15. https://doi.org/10.1177/0963662513518154.

Stofer, K. (2015). 'Connecting to agriculture in science centers to address challenges of feeding a growing population'. Science Education and Civic Engagement International Journal 7 (2). URL: http://new. seceij.net/articletype/projectr eport/connecting-to-agriculture/.

Stofer, K. A., Lundgren, L., Dunckel, B. A., Krieger, J., James, V. and Lange, M. (2019, submitted for publication). 'Public engagement on climate and health in museums and community discussions may foster behavior change'.

Suhay, E. and Druckman, J. N. (2015). 'The politics of science: political values and the production, communication and reception of scientific knowledge'. The ANNALS of the American Academy of Political and Social Science 658 (1), pp. 6-15. https://doi.org/10.1177/0002716214559004.

Swim, J. K., Geiger, N., Fraser, J. and Pletcher, N. (2017). 'Climate change education at nature-based museums'. Curator: The Museum Journal 60 (1), pp. 101-119. https://doi.org/10.1111/cura.12187.

van der Linden, S. L., Leiserowitz, A. A., Feinberg, G. D. and Maibach, E. W. (2015). 'The Scientific Consensus on Climate Change as a Gateway Belief: Experimental Evidence'. PLOS ONE 10 (2), e0118489. https://doi.org/10.1371/journal.pone.0118489.

Visser, J. (2010). Guest post: one museum's experiment with threaded comment stations. URL: http://museumtwo. blogspot.com/2010/09/guest-post-one-museums-ex periment-with.html.

Wynne, B. (1992). 'Misunderstood misunderstanding: social identities and public uptake of science'. Public Understanding of Science 1 (3), pp. 281-304. https://doi.org/10.1088/0963-6625/1/3/004.

- (2006). 'Public Engagement as a Means of Restoring Public Trust in Science Hitting the Notes, but Missing the Music?' Community Genetics 9 (3), pp. 211-220. https://doi.org/10.1159/000092659.

Zorn, T. E., Roper, J., Weaver, C. K. and Rigby, C. (2012). 'Influence in science dialogue: individual attitude changes as a result of dialogue between laypersons and scientists'. Public Understanding of Science 21 (7), pp. 848-864. https://doi.org/10.1177/0963662510386292.

Authors

Lisa Lundgren: Dr. Lisa Lundgren is a postdoctoral research associate in the Department of Forestry \& Environmental Resources at North Carolina State University. Her research employs a design-based research perspective to develop theoretical insights related to the practice of learning. She specifically focuses on the design and development of social media for informal science learning environments. E-mail: lisa.lundgren21@gmail.com. 
Kathryn (Katie) A. Stofer: Dr. Katie Stofer is a research assistant professor at the University of Florida in the Department of Agricultural Education and Communication (AEC). She focuses her research on Science, Technology, Engineering, and Math (STEM) education, especially in free-choice or informal education and outreach settings, with an emphasis on making STEM evident in agricultural education. E-mail: stofer@ufl.edu.

Betty A. Dunckel: Dr. Betty A. Dunckel has worked in informal science education settings for $40+$ years. She is the recently retired Center Director/Associate Scientist for the Center for Science Learning at the Florida Museum of Natural History. She has developed numerous programs that promote science interest and understanding for diverse audiences, and also works with exhibit development, visitor research, and program and exhibit evaluation.

E-mail: badunckel@gmail.com.

Janice Krieger: Dr. Janice Krieger is a professor in the Advertising Department and serves as Director of the STEM Translational Communication Center in the College of Journalism and Communications. E-mail: janicekrieger@ufl.edu.

Makenna Lange: during the development and writing of this publication, Makenna Lange was a graduate research assistant in the Department of Agricultural Education and Communication at the University of Florida.

E-mail: makennalange@gmail.com.

Vaughn James: during the development and writing of this publication, Vaughan James was a graduate research assistant in the Department of Agricultural Education and Communication at the University of Florida.

E-mail:vaughan5@ufl.edu.

\section{How to cite}

Lundgren, L., Stofer, K. A., Dunckel, B. A., Krieger, J., Lange, M. and James, V. (2019). 'Panel-based exhibit using participatory design elements may motivate behavior change'. JCOM 18 (02), A03. https:/ / doi.org/10.22323/2.18020203. 